Vol. 1, No. 1, 2019

https://doi.org/10.23939/cds2019.01.061

UDC 534.843:004.9

M. Melnyk

Lviv Polytechnic National University

\title{
DEVELOPMENT OF A METHOD FOR AUTOMATED SELECTION OF SOUND ABSORBTION COEFFICIENTS
}

\author{
(C) Melnyk M., 2019
}

The article describes a method for automated selection of sound energy absorption coefficients of different materials. The method provides means to calibrate inner space models in software systems that simulate acoustic properties on the example of the Catt-Acoustic system. The reflection of the sound in a synagogue has been investigated and ways to reduce it have been proposed to improve the language comprehensibility index.

Key words: Catt-Acoustic, sound absorption coefficient, acoustic properties of inner spaces, reverberation time.

\section{Introduction}

The reverberation time is one of the most important parameters that characterizes acoustic quality of inner spaces [1-3]. This parameter is often used to calibrate the model. For example, if there is a need to create a model of inner space to study its acoustic characteristics or to improve them, then one of the ways to obtain an accurate model is the appropriate selection of the coefficients of sound absorption of materials of walls, ceilings, floors, decoration, etc. There are no optimization modules present in CATT-Acoustic or similar systems that automatically select proper materials. In connection with this the task was set to find a way of quick selection of the appropriate sound absorption coefficients. For the model to be considered acceptable it must be calibrated according to the experimentally determined reverberation time. The difference between model and experiment results cannot be more than $5 \%$. For that matter it may take a long time to select the sound absorption coefficients.

\section{Development of the inner space model}

The Zori Guild Synagogue, Lviv, Ukraine was selected to investigate the effectiveness of the designed method. The inner space of the Zori Guild Synagogue is shown in Fig. 1fig. 1. This inner space has $230 \mathrm{~m}^{2}$ in area and the volume is $2465 \mathrm{~m}^{3}$. The ceiling height is $14 \mathrm{~m}$.

A model view of the inner space under consideration in the Catt-Acoustic system is presented in Fig. 2.

Reverberation time in octave bands

\begin{tabular}{|c|c|c|c|c|c|c|c|c|}
\hline \multirow{2}{*}{ Method } & \multicolumn{9}{|c|}{ Frequency, $[\mathrm{Hz}]$} \\
\cline { 2 - 9 } & 125 & 250 & 500 & $1 \mathrm{k}$ & $2 \mathrm{k}$ & $4 \mathrm{k}$ & $8 \mathrm{k}$ & $16 \mathrm{k}$ \\
\hline Eyring & 2.84 & 3.01 & 3.43 & 3.58 & 3.05 & 2.5 & 1.2 & 0.41 \\
\hline Sabine & 2.96 & 3.12 & 3.54 & 3.67 & 3.13 & 2.54 & 1.21 & 0.41 \\
\hline T-30 & 3.3 & 3.17 & 3.58 & 3.78 & 3.26 & 2.65 & 1.23 & 0.41 \\
\hline
\end{tabular}

As can be seen from Table 1, the results obtained by calculations using Eyring [4], Sabine equations [5] and ones obtained by simulation, which are designated as T-30, are similar. However, the most accurate are the simulation results. We suggest taking them as a basis for our further consideration. It follows from the simulation results that the average reverberation time is 3.3 seconds. To increase language comprehension, the task was set to reduce the average time to 1.75 seconds. 


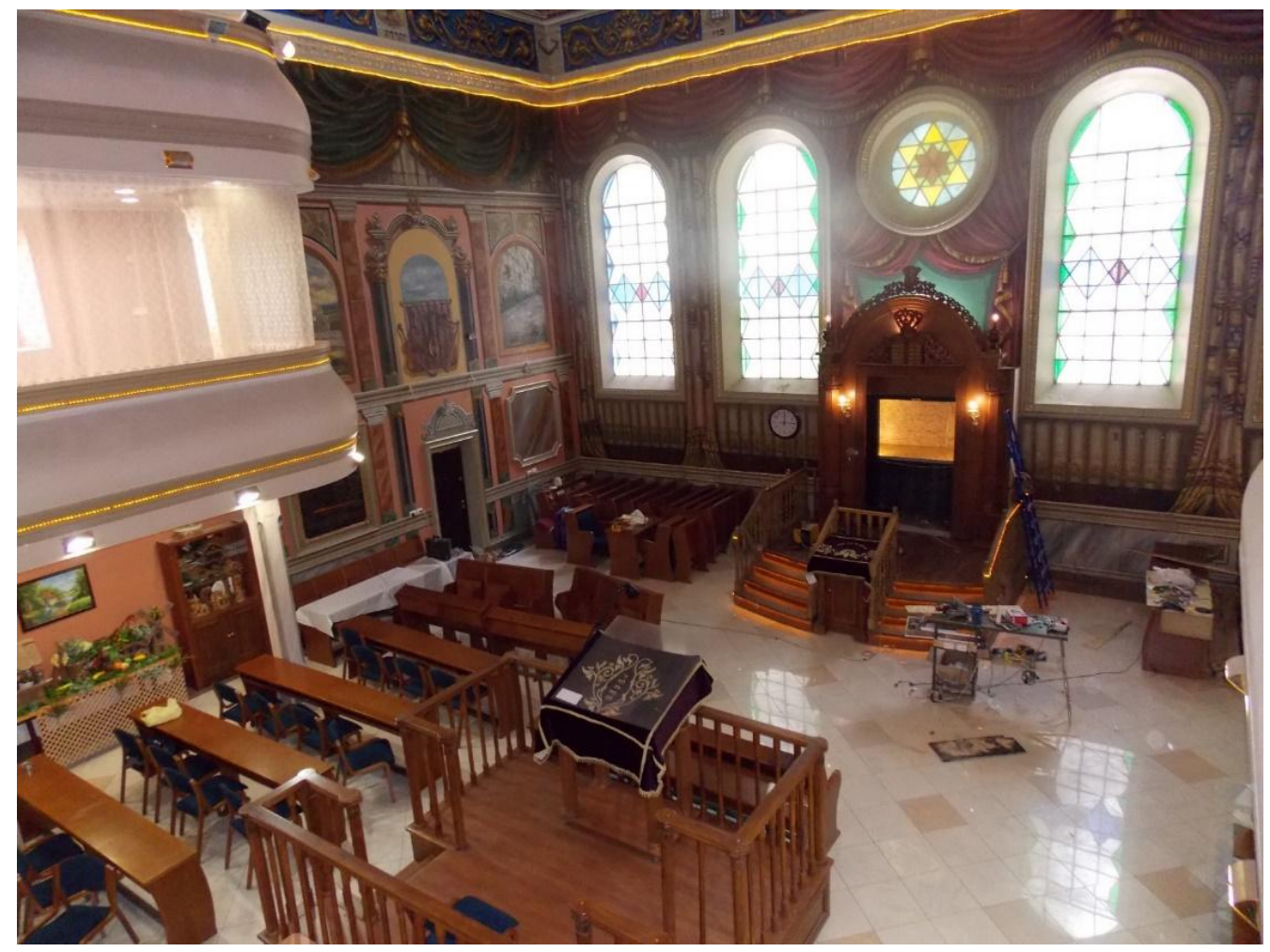

Fig. 1. Inner space of the Tsori Gilod Synagogue, Lviv, Ukraine

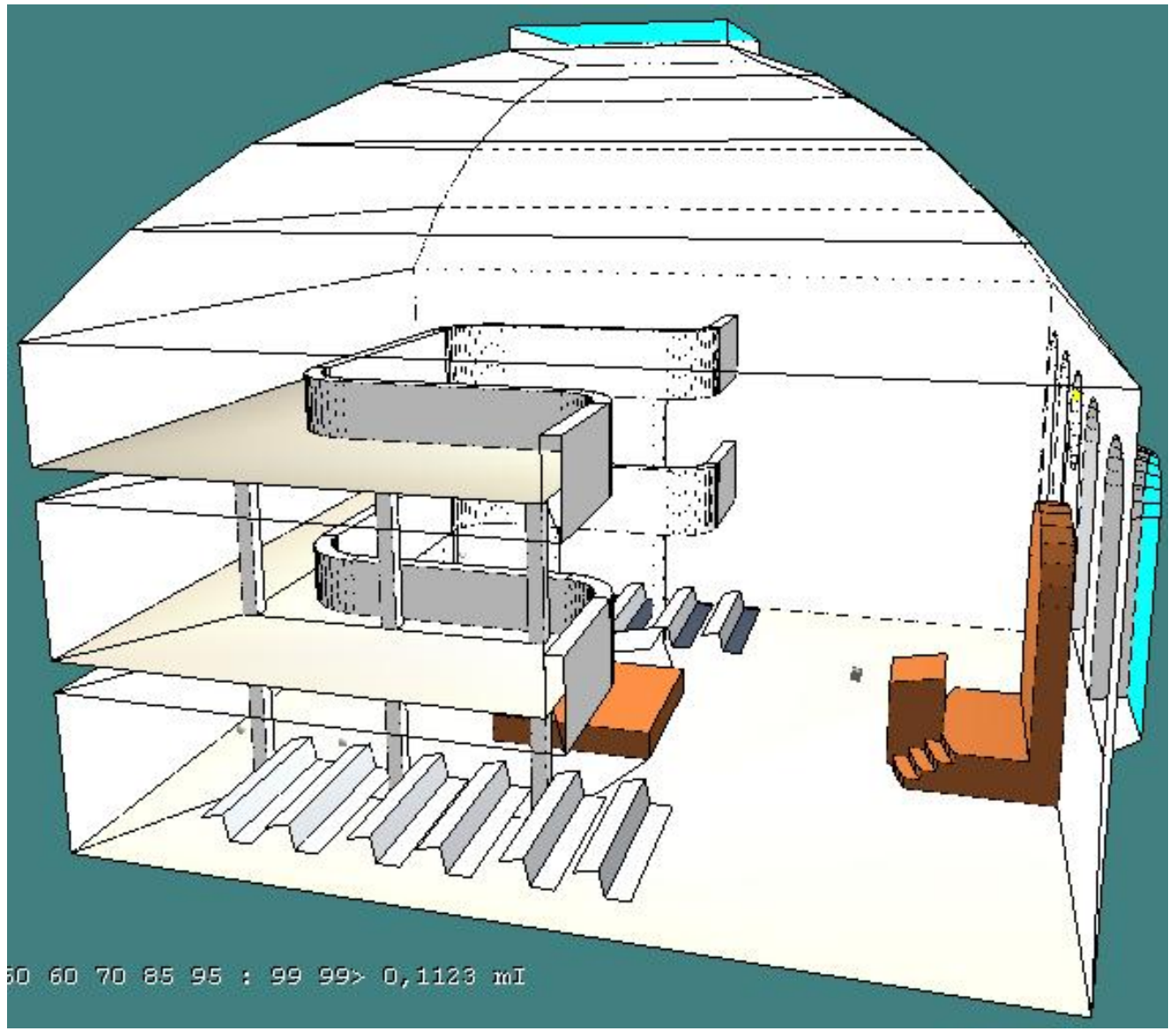

Fig. 2. Model of the Tsori Gilod Synagogue's inner space presented in the Catt-Acoustic system 
At the first stage it was suggested to use a reflective surface of transparent plastic so that not to obscure the architecture to obtain more direct sound energy. The result was not significantly improved, was costly, and had a negative impact on the appearance of the synagogue (see Fig. 3).

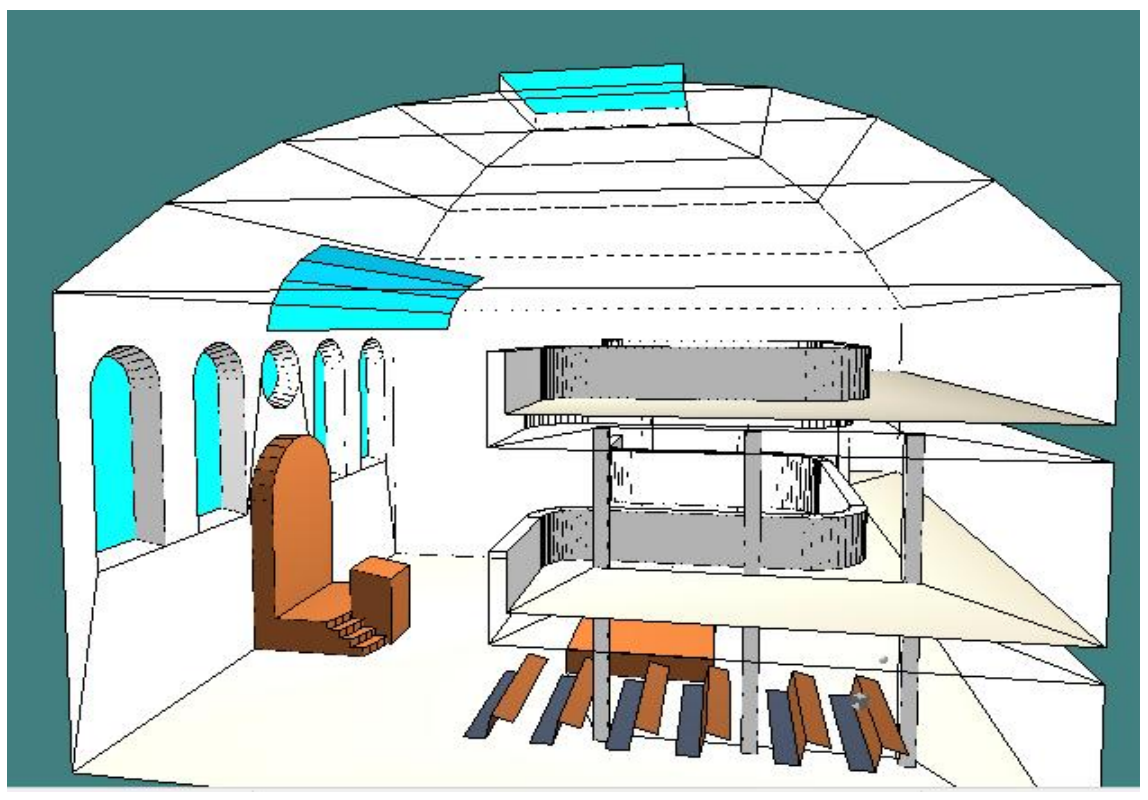

Fig. 3. Model of the synagogue with a reflecting surface

Having taken this into consideration, it was suggested to investigate the utilization of the fitted carpet on the floor to achieve the desired reverberation time (see Fig. 4).

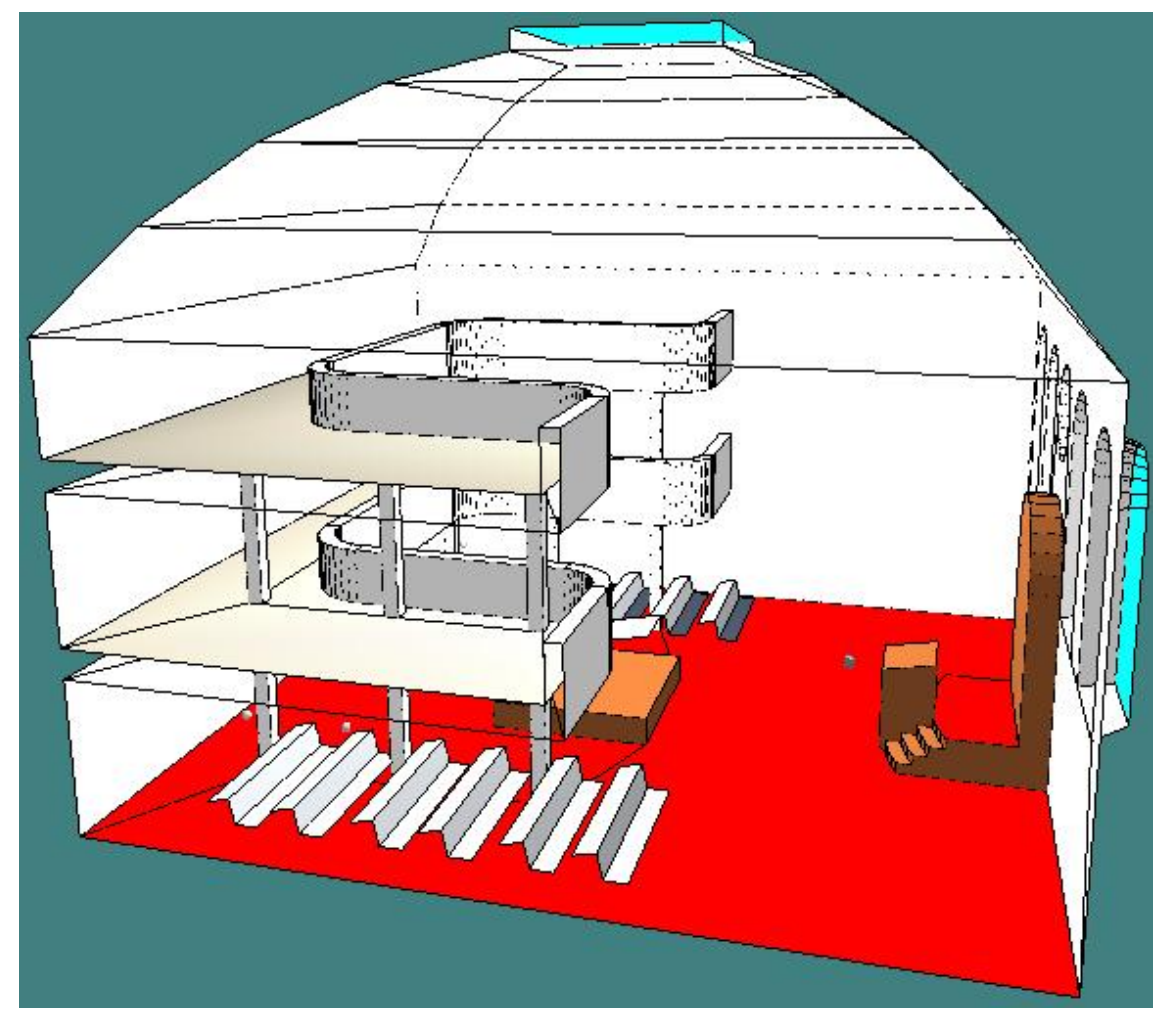

Fig. 4. Model of the synagogue with the fitted carpet on the floor 


\section{Development of the method for automated selection of absorption coefficients}

It takes a lot of time to choose the appropriate absorption coefficients, and accordingly the task was to find ways to automate the process. The proposed method is presented in Fig. 5.

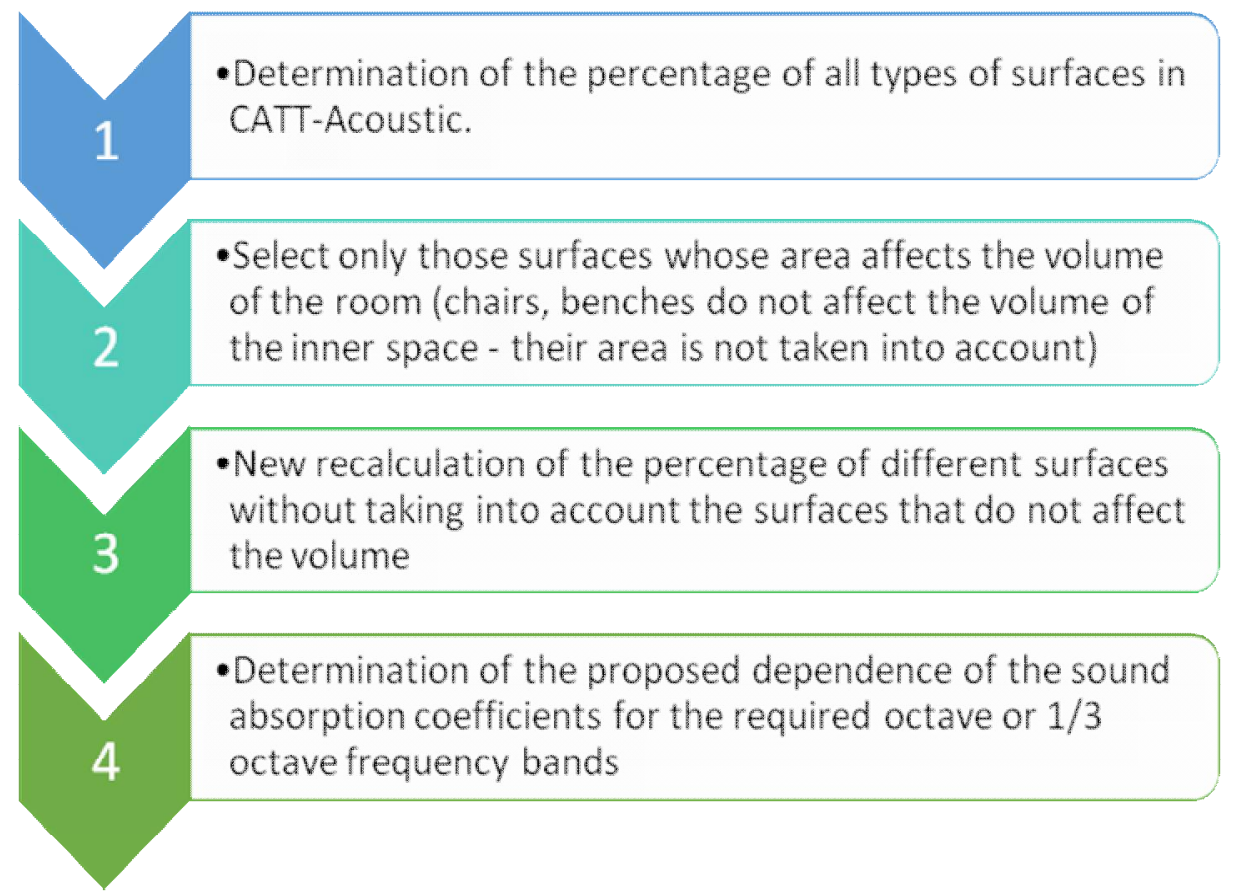

Fig. 5. The method of selection of absorption coefficients

Reverberation time $\mathrm{T}$ is the time during which the sound pressure level decreases by $60 \mathrm{~dB}$ from the moment the sound source is switched off. It can be determined from the following dependence called the Sabine equation [6]:

$$
\mathrm{T}=\frac{0.161 V}{A}=\frac{0.161 V}{\sum_{i=1}^{n} \alpha_{i} S_{i}},
$$

where: $V$ is a volume of the inner space, $S_{i}$ is an area $i$ is a surface, $a_{i}$ is an absorption coefficient of the surface $i$.

The problem how to determine what proportion of volume is per a specific surface to be solved. Research has found that it is best to display a volume fraction due to the percentage of one surface relative to the entire volume, hence:

$$
\alpha=\frac{0.161 \cdot V_{S} \cdot p_{S}}{T \cdot S},
$$

where $p_{S}$ is a percentage of the surface whose absorption coefficients are obtained; $\alpha$ is a required absorption coefficient, Vs is a volume of the room, $p_{S}$ is a percentage of surface absorption coefficient to be determined, $\mathrm{T}$ is a reverberation time to be got, $\mathrm{S}$ is a surface area of the absorption coefficient.

We will show the work of the method by the example of a synagogue model, as in Fig. 2. The simulation results for determining the reverberation time are presented in Fig. 6.

Having applied the Save statistics function the way in which the absorption coefficients affect the reverberation time in the simulated inner space can be observed in a generated text file. The results are presented as a percentage. For example, in a file (see Fig. 7) the MDRYWALL surface covers area of $159.6 \mathrm{~m}^{2}$, but at a frequency of $500 \mathrm{~Hz}$ absorbs only $77.8 \%$ of the sound. 


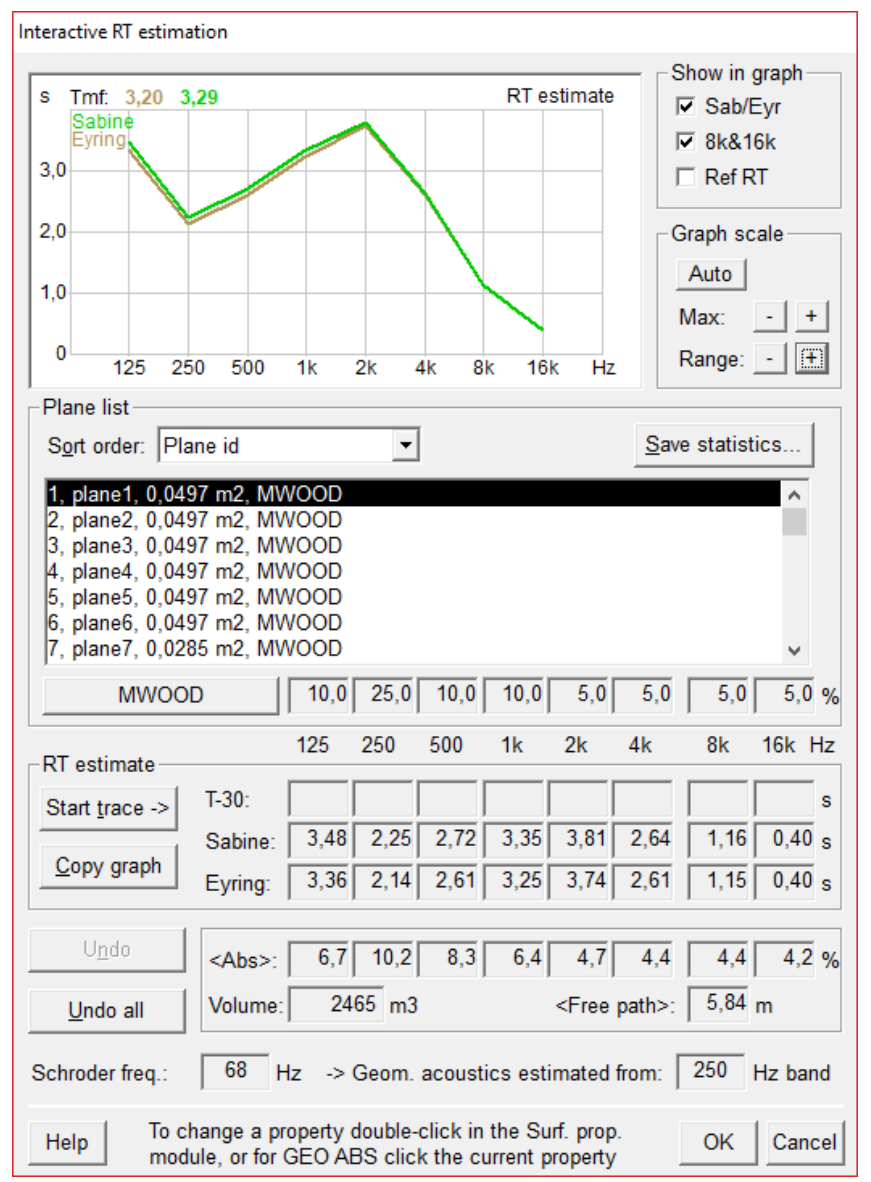

Fig. 6. Simulation results for fitted carpet

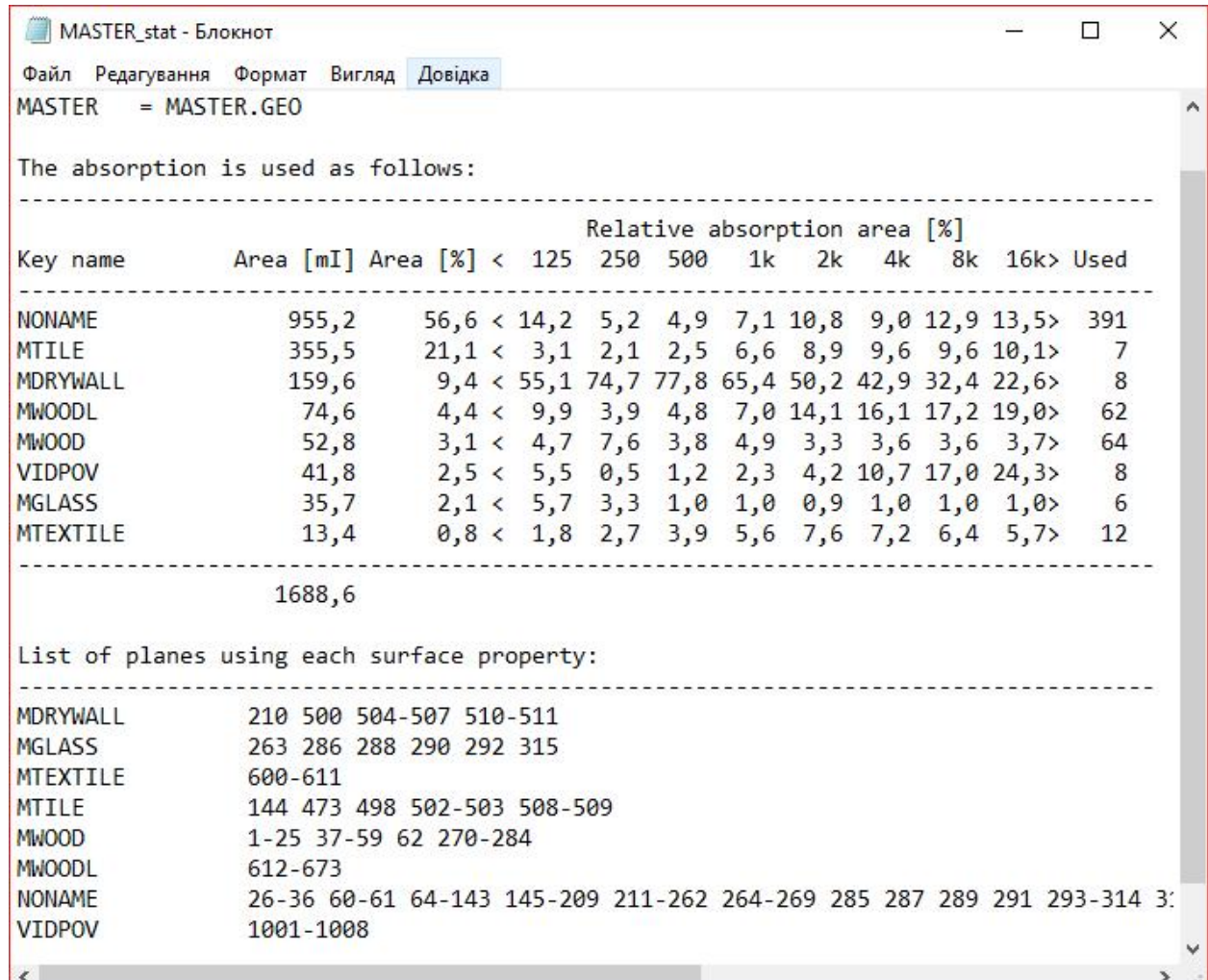

Fig. 7. Statistical information about the percentage of each surface type 
The bottom of the file also contains a list of surfaces to which this material has been applied. This information helps when building a model. For example, changing the absorption coefficient for a floor that occupies $21 \%$ of all surfaces can have a significant effect on the reverberation time, while adjusting the acoustic properties of the chairs upholstery (a surface called mTextile) will not have a significant effect and occupies only $0.8 \%$ of all surfaces.

After creating the geometry and positioning the observation points and sound sources appropriately, one needs to adjust the model. The adjustment is based on the appropriate selection of the sound absorption coefficients of the surfaces and their possible correction in order to obtain the correct simulation results. A maximum of $5 \%$ error is required relative to the values obtained from the measurements. To achieve these requirements as well as to reduce time of selecting the appropriate absorption coefficients, a method that will automate the process was proposed to develop.

Information about surface area and percentage of all surfaces obtained from CATT-Acoustic is given in Table 2.

Table 2

Information on surface area and percentage of all surfaces obtained from CATT

\begin{tabular}{|c|c|c|}
\hline Name of the surface & Area, $\left[\mathrm{m}^{2}\right]$ & Area [\%] \\
\hline FLOOR & 955.2 & 58 \\
\hline MTILE & 355.5 & 21.6 \\
\hline MDRYWALL & 159.6 & 9.7 \\
\hline MWOODL & 74.6 & 4.5 \\
\hline MWOOD & 52.8 & 3.2 \\
\hline MGLASS & 35.7 & 2.2 \\
\hline MTEXTILE & 13.4 & 0.8 \\
\hline Total & 1646.9 & 100 \\
\hline
\end{tabular}

As the volume of the inner space is not affected by benches, tables, etc., therefore, when calculating $p_{S}$ they must be discarded. Hence, Table 2 will look like the following:

Table 3

Information on the surface area and their percentage relative to all surfaces

\begin{tabular}{|c|c|c|}
\hline Name of the surface & Square, $\left[\mathrm{m}^{2}\right]$ & Square [\%] \\
\hline FLOOR & 955.2 & 61.3 \\
\hline MTILE & 355.5 & 22.8 \\
\hline MDRYWALL & 159.6 & 10.2 \\
\hline MWOODL & - & 0.0 \\
\hline MWOOD & 52.8 & 3.4 \\
\hline MGLASS & 35.7 & 2.3 \\
\hline MTEXTILE & - & 0.0 \\
\hline Total & 1558.8 & 100.0 \\
\hline
\end{tabular}


Table 2 displays statistics obtained from the Catt-Acoustic system; instead, Table 3 shows the same statistics without surfaces that do not affect the volume of the room. Based on that information the percentage of each surface should be recalculated. As we can see from the Table 3 the floor has the largest part of the area and with a slight change in the absorption coefficient we can get approximate experimental values of the reverberation time.

Similarly, this method can be used when the reverberation time parameters to be achieved are known, but one does not know what material to use.

Table 4

Actual reverberation time

\begin{tabular}{|c|c|c|c|c|c|c|c|c|}
\hline Method & \multicolumn{9}{|c|}{ Frequency, [Hz] } \\
\hline & 125 & 250 & 500 & $1 \mathrm{k}$ & $2 \mathrm{k}$ & $4 \mathrm{k}$ & $8 \mathrm{k}$ & $16 \mathrm{k}$ \\
\hline$\alpha$ & 6.16 & 8.86 & 7.9 & 6.94 & 6.723 & 4.1878 & & \\
\hline Eyring : & 2.84 & 3.01 & 3.43 & 3.58 & 3.05 & 2.5 & 1.2 & 0.41 \\
\hline Sabine : & 2.96 & 3.12 & 3.54 & 3.67 & 3.13 & 2.54 & 1.21 & 0.41 \\
\hline T-30 : & 3.3 & 3.17 & 3.58 & 3.78 & 3.26 & 2.65 & 1.23 & 0.412 \\
\hline
\end{tabular}

In order to obtain the projected reverberation time as in Table 5, we calculate what absorption coefficients a material must have to obtain such a reverberation time. The calculated coefficients are as well presented in Table 5 .

Table 5

The result with the absorption coefficients calculated according to the proposed method

\begin{tabular}{|c|c|c|c|c|c|c|c|c|}
\hline \multirow[t]{2}{*}{ Method } & \multicolumn{8}{|c|}{ Frequency, $[\mathrm{Hz}]$} \\
\hline & 125 & 250 & 500 & $1 \mathrm{k}$ & $2 \mathrm{k}$ & $4 \mathrm{k}$ & $8 \mathrm{k}$ & $16 \mathrm{k}$ \\
\hline$\alpha,[\%]$ & 12.97 & 13.66 & 14.41 & 15.26 & 16.22 & 17.30 & & \\
\hline $\begin{array}{l}\text { Reverberation } \\
\text { time is projected }\end{array}$ & 2.00 & 1.90 & 1.80 & 1.70 & 1.60 & 1.50 & & \\
\hline Eyring : & 1.87 & 2.18 & 2.16 & 2 & 1.73 & 1.34 & 0.787 & 0.341 \\
\hline Sabine : & 1.99 & 2.3 & 2.28 & 2.11 & 1.82 & 1.41 & 0.812 & 0.347 \\
\hline $\mathrm{T}-30$ & 2.1 & 2.29 & 2.25 & 2.1 & 1.83 & 1.41 & 0.811 & 0.346 \\
\hline
\end{tabular}

It is difficult to find a material with exactly the same absorption coefficients, but with approximation we found a coating of $2.4 \mathrm{~mm}$ thick, which has approximate absorption coefficients to those calculated using the proposed method.

Table 6

The result with the absorption coefficients calculated according to the proposed method

\begin{tabular}{|c|c|c|c|c|c|c|c|c|}
\hline \multirow[t]{2}{*}{ Methods } & \multicolumn{8}{|c|}{ Frequency, [Hz] } \\
\hline & 125 & 250 & 500 & $1 \mathrm{k}$ & $2 \mathrm{k}$ & $4 \mathrm{k}$ & $8 \mathrm{k}$ & $16 \mathrm{k}$ \\
\hline$\alpha,[\%]$ Calculation & 12.97 & 13.66 & 14.41 & 15.26 & 16.22 & 17.30 & \multicolumn{2}{|c|}{ Calculation } \\
\hline$\alpha,[\%]$ Fitted carpet & 10 & 16 & 15 & 30 & 50 & 47 & \multicolumn{2}{|c|}{ Fitted carpet } \\
\hline Eyring & 2.21 & 1.91 & 2.09 & 1.09 & 0.617 & 0.604 & 0.488 & 0.279 \\
\hline Sabine & 2.33 & 2.03 & 2.2 & 1.21 & 0.735 & 0.702 & 0.541 & 0.294 \\
\hline $\mathrm{T}-30$ & 2.5 & 2.01 & 2.17 & 1.15 & 0.644 & 0.636 & 0.509 & 0.289 \\
\hline
\end{tabular}

For the $8 \mathrm{kHz}$ and $16 \mathrm{kHz}$ frequencies the data are approximated because at high frequencies the attenuation in the air is greater than the absorption coefficient. 
The items contained in the synagogue have the following absorption coefficients $\alpha$ (see Table 7).

Table 7

Absorption coefficients of the inner space items (\%)

\begin{tabular}{|c|c|c|c|c|c|c|}
\hline Frequency $(\mathrm{Hz})$ & 125 & 250 & 500 & 1000 & 2000 & 4000 \\
\hline Wooden surface & 10 & 10 & 10 & 5 & 5 & 5 \\
\hline Plaster & 13 & 13.65 & 14.4 & 15.3 & 16.2 & 17.3 \\
\hline Benches & 10 & 10 & 10 & 5 & 5 & 5 \\
\hline Ceramic tile & 1 & 1 & 1 & 2 & 2 & 2 \\
\hline Drywall & 29 & 10 & 5 & 4 & 7 & 9 \\
\hline Windows & 28 & 16 & 4 & 3 & 2 & 2 \\
\hline Upholstery of chairs & 10 & 10 & 35 & 72 & 95 & 90 \\
\hline
\end{tabular}

A sound source with the following sound pressure level and volume in the specified frequency range was selected for the acoustic analysis (see Table 8):

Table 8

Audio Source Settings

\begin{tabular}{|c|c|c|c|c|c|c|c|c|}
\hline Frequency $(\mathrm{Hz})$ & 63 & 125 & 250 & 500 & 1000 & 2000 & 4000 & 8000 \\
\hline Volume $(\mathrm{dB})$ & 94.0 & 94.0 & 94.0 & 94.0 & 94.0 & 94.0 & 94.0 & 94.0 \\
\hline
\end{tabular}

\section{Checking the correctness of the method}

In order for the model to be considered acceptable, it is necessary that the simulation results and the results obtained through the experiments differ by no more than $5 \%$.

It must be remembered that the adjusted absorption characteristic matches the physical properties of the material (for example, drywall wall should be interpreted as having a higher absorption coefficient than the drywall board itself, since it still has a space between the board and the wall, and sometimes mineral wool). Experimental measurements of reverberation time will be performed without people present, so the absorption coefficients for surfaces that simulate surfaces where people are located should have appropriate values.

When building a model, you should use a material statistics file generated using the Interactive RT estimate tool.

The absorption of surfaces opposite the scene is of great importance. Attention should be paid to such large surfaces as the floor and ceiling. After creating a model, we can begin to evaluate the acoustic quality of the inner space, depending on the function that the inner space has to perform in terms of acoustics.

The graph presented the simulation results shows (upper curve), with such arrangement of the synagogue as it is now the reverberation time is more than 3 seconds, which causes the poor intelligibility of the language. For clarity the most useful reverberation time is $0.6-1.6 \mathrm{sec}$. With a small volume of synagogue's inner space, it is difficult to achieve such a small amount of reverberation time. In case of applying materials with a high absorption coefficient the volume will be lost in the distance from the source (the rabbi leading the sermon). As in synagogues mostly sermons are conducted the language comprehension is of paramount importance.

The red curve in the graph shows the time that we would like to get by picking up the appropriate absorption coefficients.

Using the designed method for selection of absorption coefficients we have selected the corresponding absorption coefficients for the floor covering material by one iteration. Comparing the purple curve with the red one, we can observe that the results are not greater than $0.5 \mathrm{sec}$. Having picked up material with approximate sound absorption characteristics, we obtained an reverberation time with the 
real material - this is a green curve that shows the reverberation time when modifying an inner space with a fitted carped. Because it is difficult to find a material with specific parameters, we have obtained a similar one, the absorption coefficients of which in the low and medium frequencies gave approximately the expected cost of the reverberation time. On the other hand, at high frequencies the use of this material resulted in a much lower reverberation time, which is even better for language comprehension.

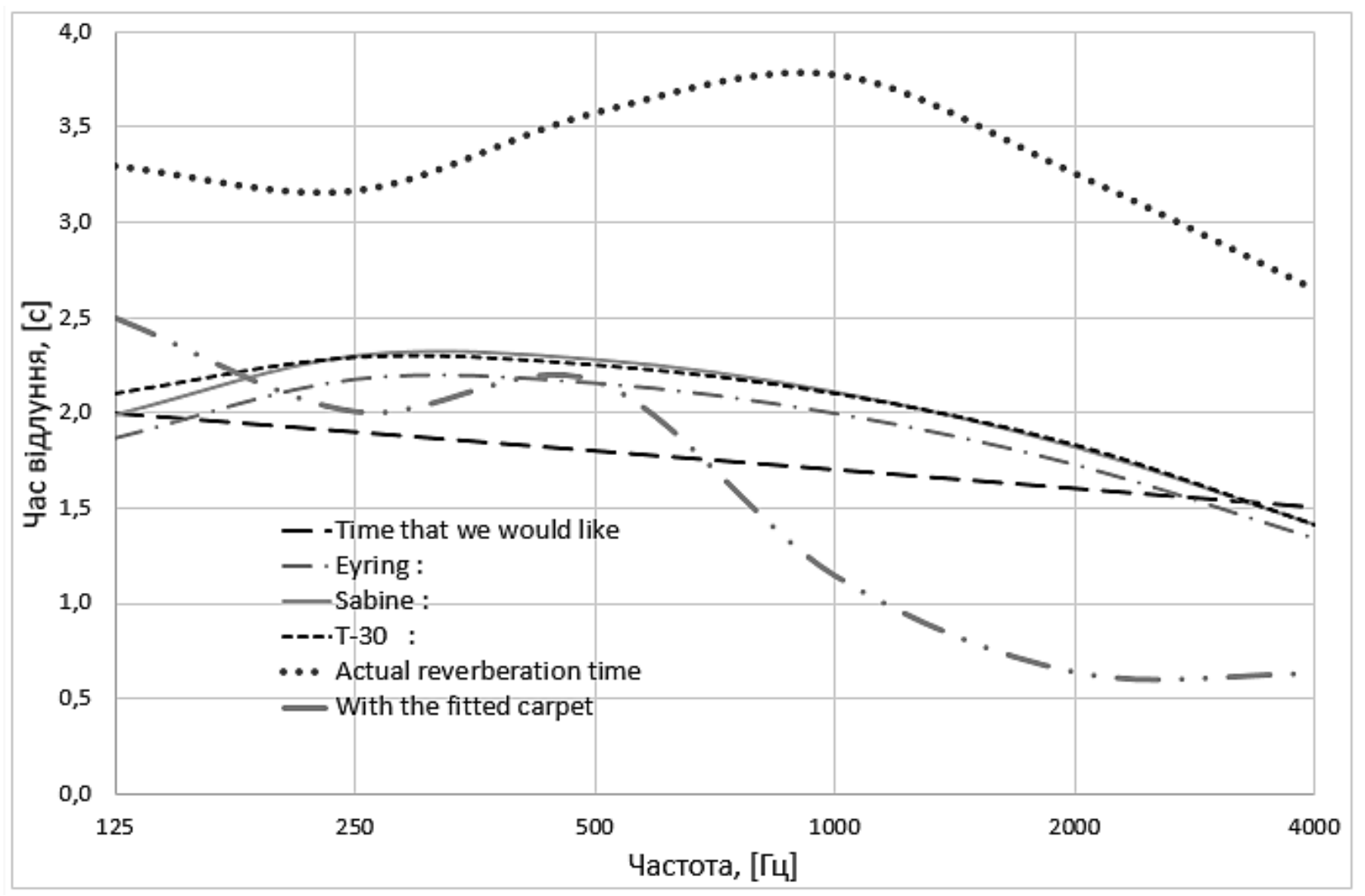

Fig. 8. Reflection time results for different modeling options

\section{Conclusion}

The method for selection of acoustic absorption coefficients for the Catt-Acoustic acoustic modeling system was developed, which consists in reversing the coefficients through the Sabine equation and allows only one iteration to achieve an accuracy of reverberation time determination of up to $0.5 \mathrm{~s}$.

Studies have been conducted to establish that, the as-is synagogue arrangement a reverberation time is more than 3 seconds which has a bad effect on language comprehension. Studies have shown that the cheapest way that will not change the architecture, which is of historic value, is to use a soft absorbent floor on the ground floor and on balconies that absorb significant first reflections from the dome, thus reducing reverberation time.

The developed method was used to select the required material. The following modification of the synagogue's inner space was proposed - use fitted carpet which made it possible to achieve an average reverberation time less than 1.75 seconds, which should significantly increase the intelligibility of speech on the balconies and in the distance from the speaker. 


\section{References}

1. Standard, ISO. (1997). 3382. Acoustics-Measurement of the reverberation time of rooms with reference to other acoustical parameters. International Standards Organization.

2. Vorländer, M., \& Bietz, H. (1994). Comparison of methods for measuring reverberation time. Acta Acustica united with acústica, 80(3), pp. 205-215.

3. Champagne, B., Bédard, S., \& Stéphenne, A. (1996). Performance of time-delay estimation in the presence of room reverberation. IEEE Transactions on Speech and Audio Processing, 4(2), pp. 148-152.

4. Eyring, C. F. (1930). Reverberation time in "dead" rooms. The Journal of the Acoustical Society of America, 1(2A), pp. 217-241.

5. Carvalho, A. P. O. (1995). The use of the Sabine and Eyring reverberation time equations to churches. The Journal of the Acoustical Society of America, 97(5), pp. 3319-3319.

6. Young, R. W. (1959). Sabine reverberation equation and sound power calculations. The Journal of the Acoustical Society of America, 31(7), pp. 912-921.

М. Мельник

Національний університет “Львівська політехніка"

\section{РОЗРОБЛЕННЯ МЕТОДУ АВТОМАТИЗОВАНОГО ДОБОРУ КОЕФІЦІНТІВ ЗВУКО-ПОГЛИНАННЯ}

() Мельник М., 2019

У статті запропоновано метод автоматизованого добору коефіцієнтів поглинання звукової енергії матеріалами. Метод дас змогу провести калібрування моделей приміщень для програмних систем моделювання акустичних властивостей на прикладі системи Catt-Acoustic. Проведено дослідження часу відлуння синагоги та запропоновані шляхи його зменшення для покращення індексу зрозумілості мови.

Ключові слова: Catt-Acoustic, коефіціснт звукопоглинання, акустичні властивості приміщень, час відлуння. 